\title{
Behavior of two eco-compatible duplex systems used in the construction industry against corrosion
}

\author{
P.R. Seré ${ }^{\mathrm{a}, \mathrm{b}}$, C. Deyá ${ }^{\mathrm{a}, \mathrm{b}, *}$, C.I. Elsner ${ }^{\mathrm{a}, \mathrm{b}}$, A.R. Di Sarli ${ }^{\mathrm{a}}$ \\ a CIDEPINT: Research and Development Centre in Paint Technology (CICPBA-CCT CONICET LA PLATA), Av. 52 s/n entre 121 y 122. CP. \\ B1900AYB, La Plata, Argentina \\ ${ }^{\mathrm{b}}$ Engineering School, National University of La Plata, Av. 1 Esq. 47. CP. B1900TAG, La Plata, Argentina
}

\section{A R T I C L E I N F O}

Article history:

Accepted 14 November 2013

Available online 25 December 2013

Keywords:

Galvanized

Silane

Protection

Corrosion

Organic coating

Duplex system

\begin{abstract}
A B S T R A C T
Two types of coated steels are currently competing in the construction industry: the hot-dip galvanized steel (HDGS) and the 55\%Al-Zn alloy coated steel (HDZAS). Both systems are typically coated by a chromate-based conversion film, which is dangerous for human health and environment. Furthermore, for aesthetics purposes and/or to prolong their expected or planned service life, they are painted designing each paint system as a function of the service conditions to which they will be subject to. The present work reports on a comparative study of two duplex systems: steel/metal coating/organic coating. In both cases, the chromate-based pretreatment was replaced by another one that features $\gamma$ mercaptopropyltrimethoxysilane (MTMO) as an active element. The organic coating used was a waterbased polyurethane. Behavior of this paint against corrosion was assessed by exposing the samples in salt spray or humidity chambers, and monitoring its evolution by electrochemical impedance spectroscopy, visual observation, scanning electron microscopy and energy dispersive X-ray analysis. The results revealed that: MTMO was suitable for promoting adhesion both in HDGS and HDZAS; in humidity chamber, both duplex systems provided good protection; the presence of corrosion products of the base steel and paint blistering was detected in the HDGS/paint system seventy-two days after exposure; however, 150 days after that, none of these effects were observed in the HDZAS/paint system; differences in behavior were significant in Salt spray chamber: speed of paint delamination from the mark done and the bulk of corrosion products generated was much higher in HDGS/paint system than in HDZAS/paint. (c) 2013 Elsevier Ltd. All rights reserved.
\end{abstract}

\section{Introduction}

Corrosion is a major problem since it not only reduces the resistance of the structural materials and directly leads to potential harm to humans but also indirectly affects conservation of natural resources. In metals, corrosion depends on several factors including properties of the surface metal, the metal/protection film interface, physical, chemical and electrochemical properties of the protection film and the environmental conditions under which the system is exposed. To delay and/or reduce this natural thermodynamic metal tendency, metal and organic coatings, which form a protective layer onto metal surfaces, have been developed. Among the metal coatings used to prevent steel corrosion, those based on zinc or its alloys have become the most used due to their low cost and mainly to the fact that zinc is electrochemically more active than steel and therefore it protects

\footnotetext{
* Corresponding author at: CIDEPINT: Research and Development Centre in Paint Technology (CICPBA-CCT CONICET LA PLATA), Av. 52 s/n entre 121 y 122. CP. B1900AYB, La Plata, Argentina. Tel.: + 542214831141.

E-mail address: estelectro2@cidepint.gov.ar (C. Deyá).
}

steel cathodically. Also, corrosion products formed under certain exposure conditions can protect the surface providing a barrier effect [1-3]. Zinc alloys composed of $55 \%$ of $\mathrm{Al}, 1.6 \%$ of Si and $\mathrm{Zn}$ are among the alloys that provide excellent galvanic protection.

When a higher degree of protection is required, properly selected paint systems can be added to the metal protection. The combination of both protection systems (metal+organic coating), known as "duplex", has shown to provide a synergistic effect when compared with individual coatings. This higher protection against corrosion is attributed, on the one hand, to the galvanic coating layer (cathodic protection + blocking of its defects by the corrosion products) and on the other hand, to the barrier effect provided by the paint system [4-6].

It should be noted that in spite of the formation of the barrier, at least to some extent, water and oxygen can penetrate the film, even in the absence of structural defects. Therefore, adhesion between paint and metal surface also plays a major role in the system protection; the type of bond in the substrate/paint interface depends both on the chemical nature and the degree of the crosslinking of the polymer and on the type of metal substrate and its surface treatment. Basically, paint adhesion may be improved 
by applying a pretreatment to the substrate. The most widely used, to improve paint adhesion onto zinc or its alloys, are those based on chromate and phosphate. These pretreatments have long been used and are highly effective and easy to apply, however they are harmful for human health and the environment [7]. For this reason, environmentally friendly pretreatments have been lately developed,

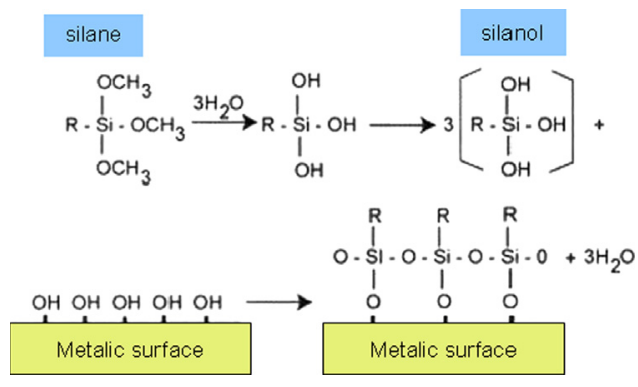

Fig. 1. Scheme of the silanes reaction.

Table 1

Coatings thickness.

\begin{tabular}{lll}
\hline Sample & Galvanic layer thickness $(\mu \mathrm{m})$ & Paint film thickness $(\mu \mathrm{m})$ \\
\hline HDGS & 26 & 115 \\
HDZAS & 35 & 120 \\
\hline
\end{tabular}

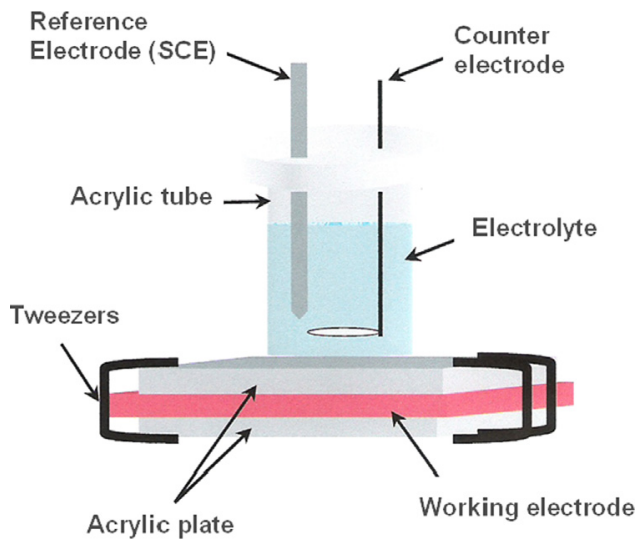

Fig. 2. Scheme of the electrochemical cell. and among them, silanes are one of the most investigated [8,9]. The general formula of these compounds is $\mathrm{R}-\mathrm{Si}-\left(\mathrm{R}^{\prime} \mathrm{O}\right)_{3}$, where $\mathrm{R}$ is a carbon chain, functionalized or not and $\mathrm{R}^{\prime} \mathrm{O}$ is a ethoxy o methoxy group, which is easily hydrolysable. $\gamma$-aminopropyltrimethoxysilane $\left(\mathrm{NH}_{2}\left(\mathrm{CH}_{2}\right)_{3} \mathrm{Si}\left(\mathrm{OCH}_{3}\right)_{3}\right)$, glycidoxypropyltrimethoxysilane $\left(\mathrm{CH}_{2} \mathrm{OCH}\right.$ $\left.\left(\mathrm{CH}_{2}\right)_{3} \mathrm{Si}\left(\mathrm{OCH}_{3}\right)_{3}\right)$ and mercaptopropyltrimethoxysilane $\left(\mathrm{HS}\left(\mathrm{CH}_{2}\right)_{3} \mathrm{Si}\right.$ $\left.\left(\mathrm{OCH}_{3}\right)_{3}\right)$ are among the most studied silanes. They form a protective film onto the substrate, which adheres to the substrate by covalent bonds of the Si-O-Metal type formed by the products of hydrolysis of the $\mathrm{R}^{\prime} \mathrm{O}$-groups and the oxi-hydroxides film present on the metal [10,11], Fig. 1.

Strictness of the environmental regulations designed to protect the public health and the environment needs systems which are developed on the base of cleaner technologies both regarding the pretreatment and the paint. Therefore, replacement of organic solvents used in paints and pretreatments is a major requirement.

The present work reports on the behavior of two "duplex" systems against corrosion: steel galvanized by hot immersion/paint and steel coated with 55\%Al-Zn alloy/paint. $\gamma$-mercaptopropyltrimethoxysilane (MTMO) was used as a pretreatment since, although it is used as a steel pretreatment, few works are available on its use on zinc as adhesion promoter. The protective ability of the systems was evaluated by two standardized accelerated assays, salt spray (SSC) or humidity and temperature controlled (HC) chambers. The deterioration level was assessed by visual observation, scanning electron microscopy (SEM), optic microscopy and electrochemical impedance spectroscopy (EIS).

\section{Materials and methods}

Samples of carbon steel SAE 1010 of commercial origin coated with zinc or $55 \% \mathrm{Al}-\mathrm{Zn}$ alloy by continuous hot-dip process were used as substrates. All the samples $(15 \times 7.5 \times 0.70 \mathrm{~cm})$ were subjected to electrochemical cleaning by immersion in a $10 \% \mathrm{p} / \mathrm{v}$ $\mathrm{NaOH}$ solution for $20 \mathrm{~s}$ and application of a $9 \mathrm{~A}$ current. To assess the effect of $\gamma$-mercaptopropyltrimethoxysilane (MTMO) as an adhesion promoter, some samples were pretreated with silane.

The pretreatment solution was prepared as follows: $3.6 \mathrm{~mL}$ of MTMO were mixed with $5.4 \mathrm{~mL}$ of a $60 \%(\mathrm{v} / \mathrm{v})$ methanol solution and $40 \% \mathrm{v} / \mathrm{v}$ of distilled water. The $\mathrm{pH}$ of this solution was adjusted to 4.0 with acetic acid prior to addition of silane [12]. After $1 \mathrm{~h}$ of hydrolysis with constant agitation, the solution obtained was diluted with $81.3 \mathrm{~mL}$ of the methanol-distilled water solution. The final concentration of MTMO was $4 \% \mathrm{v} / \mathrm{v}$. The samples were immersed in a solution of hydrolyzed MTMO for $1 \mathrm{~min}$, cured in vertical position in a furnace at $80 \pm 1{ }^{\circ} \mathrm{C}$ for $10 \mathrm{~min}$ [12], and kept at room temperature until painted. The untreated samples (without

Table 2

Adhesion test results.

\begin{tabular}{lll}
\hline Sample & $\begin{array}{l}\text { Classification } \\
\text { (ASTM D-3359) }\end{array}$ & $\begin{array}{l}\text { Percentage of } \\
\text { delaminated area }\end{array}$ \\
\hline HDGS & 1B & 64 \\
HDGS + MTMO & B & 4 \\
HDZAS & 3B & 12 \\
HDZAS + MTMO & 5B & 0 \\
\hline
\end{tabular}

Classification of the adhesion degree according to the delaminated area.

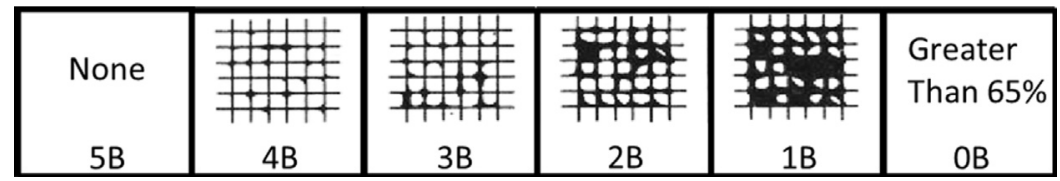


MTMO) were used as controls. All the samples were coated with a water polyurethane-based paint developed at CIDEPINT. This paint contained $3.79 \%$, by weight, of ocher "ferrite" as pigment, $8.75 \%$ of isocyanate converter and $87.46 \%$ of the acrylic resin. To ensure the appropriate curing process of the paint, the samples painted were kept in a desiccator at $25^{\circ} \mathrm{C}$ for $72 \mathrm{~h}$.

The metal coating and the dried organic film thicknesses (Table 1) were measured by optic microscopy and the magnetic method (ASTM B 499 standard), respectively.

The metal/paint film adhesion was assessed by the Tape Test method, ASTM D 3359 standard. In this test 6 cuts, through the film to the substrate, $2 \mathrm{~mm}$ apart were done with a cutting tool on the clean painted surfaces; additional cuts were done at $90^{\circ}$ to and centered on the original cuts. Then, the surface is brushed to remove detached flakes and a tape is place over the grid. Within $90 \pm 30 \mathrm{~s}$ the tape is removed and the areas inspect for removal of coating from the substrate or from a previous coating using a magnifier.

After curing the paint films, the samples were cut to reach the substrate in an area close to the edges to simulate a service failure, and they were then exposed in HC (ASTM D 2247) or in SSC (ASTM B 117) by triplicate. Periodically, the samples were photographed, visually observed and the impedance spectra were recorded.

Each electrochemical cell was built using an acrylic tube tightly bound to the painted sample by means of an o'ring and four clamps; the area exposed was $15.9 \mathrm{~cm}^{2}$ (Fig. 2). For simulating the ambient where the samples were exposed, $0.5 \mathrm{M} \mathrm{NaCl}$ solution or distilled water was used as electrolyte for those exposed in $\mathrm{HC}$ or SSC, respectively. The counter and reference electrodes were a large platinum mesh and a saturated Calomel electrode (SCE), respectively. The impedance spectra, in the corrosion potential, were performed in the potentiostatic mode using a sinusoidal signal of $15 \mathrm{mV}$ over the frequency range from $1.10^{-2}$ to $1.10^{5} \mathrm{~Hz}$. Because it is considered as the total resistance of the system [1316], the value of the impedance modulus at low frequencies was selected as the assessment parameter of the system behavior against corrosion.

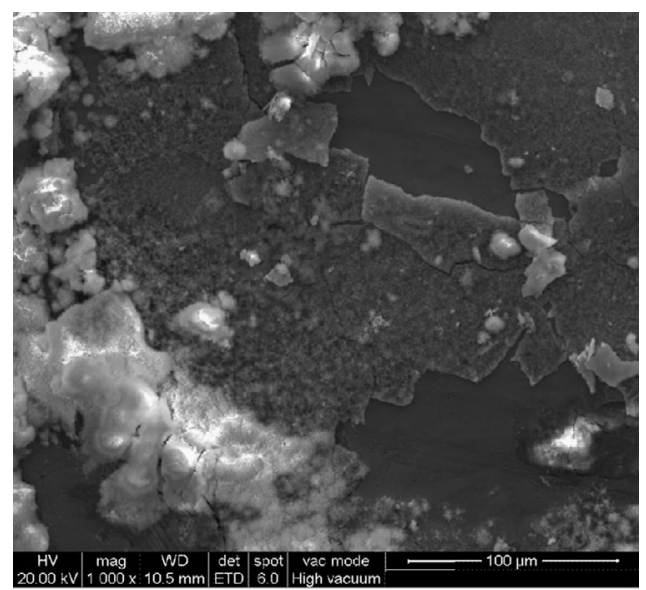

Fig. 3. Photograph of the zinc oxides/hydroxides on zinc $(1000 \times)$.

\section{Results and discussion}

\subsection{Adhesion}

Table 2 shows results of dry adhesion measurements (after being painted, cured and before being exposed to the aggressive media). The obtained results revealed that on both substrates the pretreatment with MTMO improved adhesion due to the fact that MTMO form covalent $\mathrm{Si}-\mathrm{O}-\mathrm{M}$ bonds with the metal substrate and the functional groups of the silane are compatible with the organic groups present in the paint. The electrochemical cleaning promotes the adhesion of the silane films to the substrate [17]. Conversely, in the adhesion test, failure of zinc/zinc oxyhydroxide interface appears if the paint is applied directly onto a sample after the electrochemical cleaning treatment, due to the fact that the metal surface is composed of zinc oxy-hydroxides that form a poorly adherent, fragile film on the zinc, Fig. 3. The low adhesion values of the paint/HDGS sample without treatment were attributed to this fact. However, the adhesion on the HDZAS sample without treatment was acceptable, since after the electrochemical cleaning aluminum oxide-hydroxides are formed on the sample's surface, which unlike those formed on the zinc make a compact, continuous film, adherent on the Al-Zn alloy surface. Although these compounds are very stable and do not form strong chemical bonds with the paint, the paint wets and penetrates the surface reaching the valleys of the denditric structure, which is
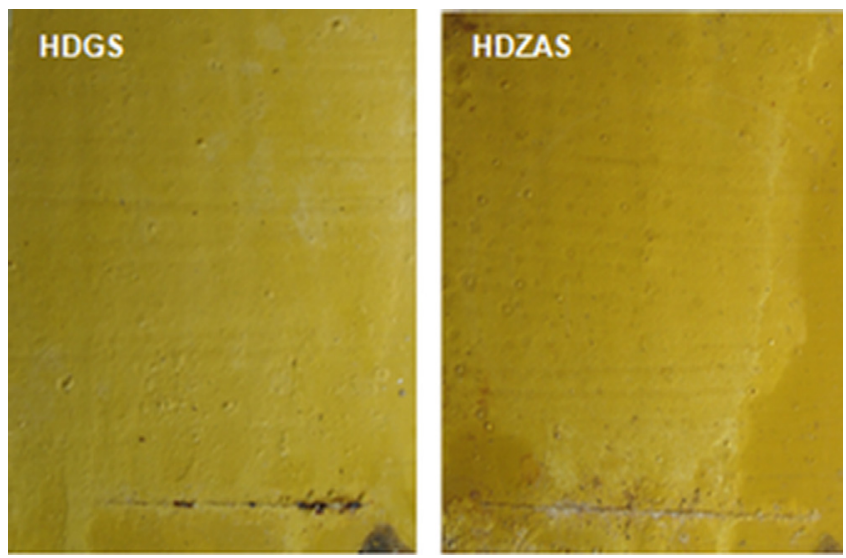

Fig. 4. Photograph of the samples after 150 days of exposure in HC.

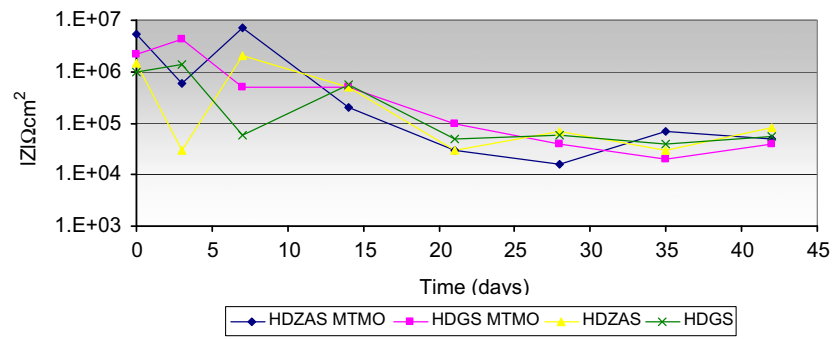

Fig. 5. Evolution of the impedance modulus at low frequencies in HC.

Table 3

Classification of the blistering degree.

\begin{tabular}{|c|c|c|c|c|}
\hline \multicolumn{5}{|c|}{ Blistering degree } \\
\hline Frequency & Dense, D & Medium dense, MD & Medium, M & Few, F \\
\hline Size & No blistering: 10 & Smaller size blister easily seen by unaided eye: 8 & Progressively larger sizes: $6,4,2$ & \\
\hline
\end{tabular}


characteristic of this alloy. Thus, an adequate mechanical anchorage is obtained.

\subsection{Aging in humidity chamber}

All duplex systems featured very good behavior in HC. One hundred and fifty days after exposure and according to standard ASTM D 714, the level of blistering was 6F for all the cases (see Table 3 for the classification of the blistering degree). No marked influence of the pretreatment with MTMO was observed in this test (Fig. 4). However, in the painted HDGS samples 72 days after exposure, steel corrosion products appeared in the area where a cut had been done through the paint to reach the steel substrate. The HDZAS only presented white corrosion products, which were attributed to deterioration of the inorganic coating.

The impedance spectra obtained throughout the exposure in $\mathrm{HC}$ allowed evaluating the evolution of the impedance module at low frequency, Fig. 5. As seen, all the tested duplex systems showed similar behavior. Fluctuations of the impedance modulus values observed in some cases were attributed to the dynamic behavior of the interface processes occurring in these systems, since when the electrolyte spreading throughout some of the coating defects reaches the metal substrate it produces formation of the electrochemical double layer on the active metal and the total impedance value decreases. This reduction is attributed to two factors: on the one hand, the formation of dysfunctional channels throughout the organic coating that reduce its resistance to water, oxygen and other species permeation and, hence, promoting corrosion of the zinc substrate and, on the other hand, these elements lead to the formation of an electrolyte film at the zinc/paint interface that reduces the charge transfer resistance

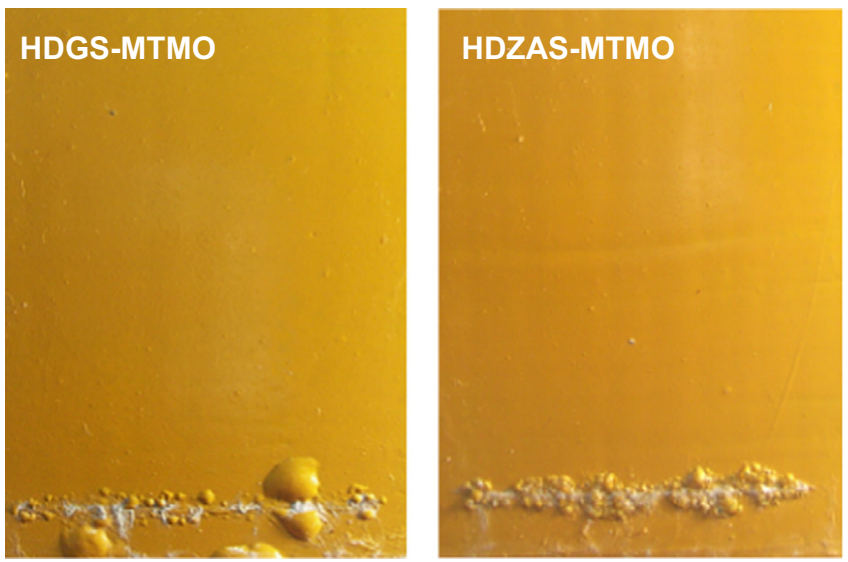

Fig. 6. Photograph of the samples after 42 days of exposure in SSC.
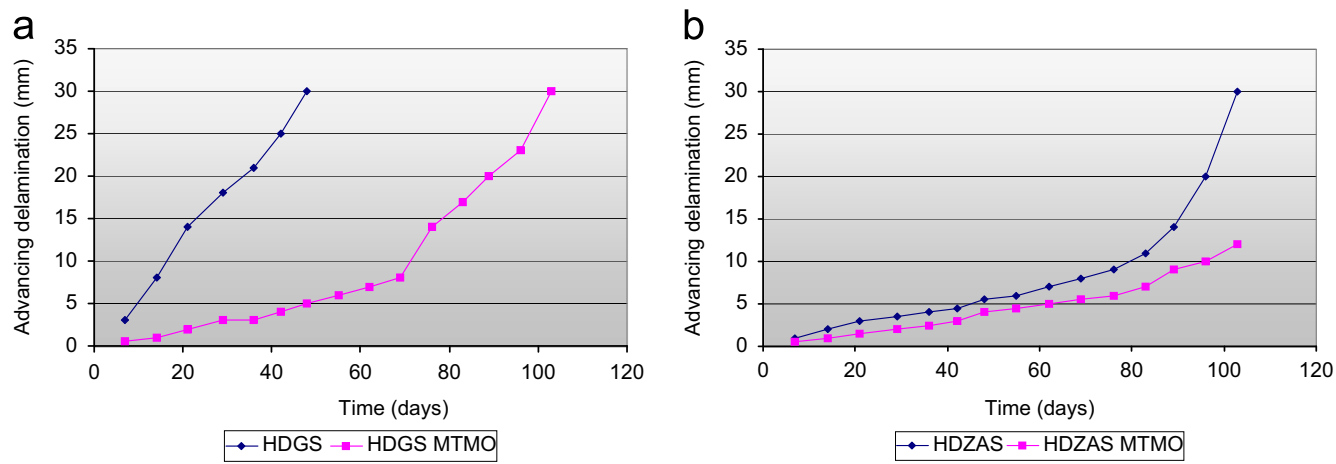

Fig. 7. Evolution of the blistering from the scribe in SSC; comparison with and without pretreatment (a) HDGS, (b) HDZAS. and, therefore facilitates the metal dissolution. However, if the dielectric characteristics of the corrosion products formed contributed to seal these defects, they would contribute to the increase of the impedance value as a function of the exposure time. Unfortunately, in this case the tendency was that such value slowly decreased until reaching certain stabilization in approximately $5-7 \times 10^{4} \Omega \mathrm{cm}^{2}$ at 42 days after exposure. This stabilization indicates that deterioration of the metal/paint system had started to evolve even more slowly, probably due to an accumulation of the corrosion products located at the bottom and/or within the coating defects.

The EIS results are consistent with the visual observation, since the degradation of all the tested duplex systems was slow and no influence of the pretreatment with MTMO was found.

\subsection{Aging in salt spray chamber}

Fig. 6 shows the results after 42 days of exposure in the SSC. The undamaged samples' area presented no blisters or corrosion signs after the test.

This test revealed clear differences regarding the evolution of the organic coating delamination from the cut. The HDGS samples showed a paint film delamination rate of $0.6 \mathrm{~mm} /$ day, which was constant during the test, while the corresponding to the HDGS+ MTMO samples was about $0.1 \mathrm{~mm} /$ day 50 days after the test. This implies that the pretreatment with MTMO considerably increases the wet adhesion of the paint/zinc substrate, reducing the delamination rate by $83.3 \%$. Although after 50 days exposure the delamination rate of the HDGS + MTMO samples increases, it is just after 105 days that it reaches the same blistering level presented by the HDGS samples after 50 days, Fig. 7a. The HDZAS samples revealed the same tendency, however, differences in the behavior were less marked after 82 days exposure, with a delamination rate of 0.13 and $0.08 \mathrm{~mm}$ /day for HDZAS and HDZAS+MTMO samples, respectively. These differences were more visible after longer testing times since HDZAS samples became more deteriorated at a speed of $0.7 \mathrm{~mm} /$ day, Fig. 7b.

The evolution of the impedance modulus at low frequencies corresponding to samples exposed in SSC showed significant differences, Fig. 8. The best and most stable behavior was shown by the HDZAS + MTMO system since the values of its IZI remained greater than $1 \times 10^{7} \Omega \mathrm{cm}^{2}$ during the whole test. The poorest performance was exhibited by the HDGS samples whose $|Z|$ was $3.2 \times 10^{3} \Omega \mathrm{cm}^{2}$ at the end of the test. Fig. 8 also shows that the behavior of the HDZAS and HDGS + MTMO samples was similar.

The difference in the behavior of both substrates without pretreatment is attributed to the fact that in HDGS, the $\mathrm{Cl}^{-}$anions contained in the electrolyte react with the substrate forming corrosion products mostly composed of hexagonal crystals of 


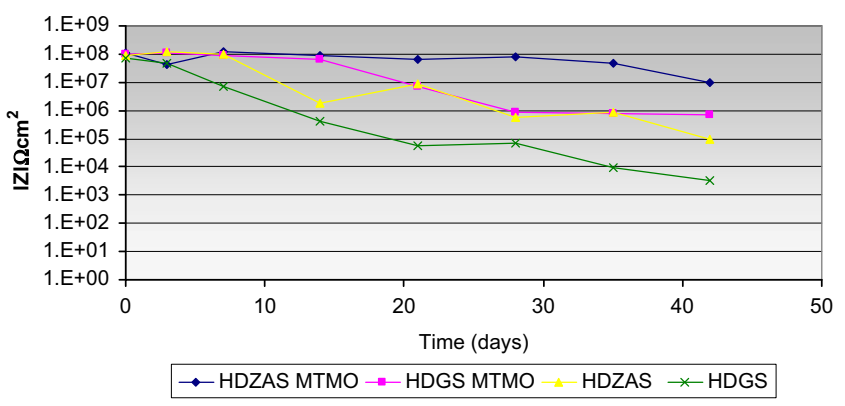

Fig. 8. Evolution of the impedance modulus at low frequencies in SSC.

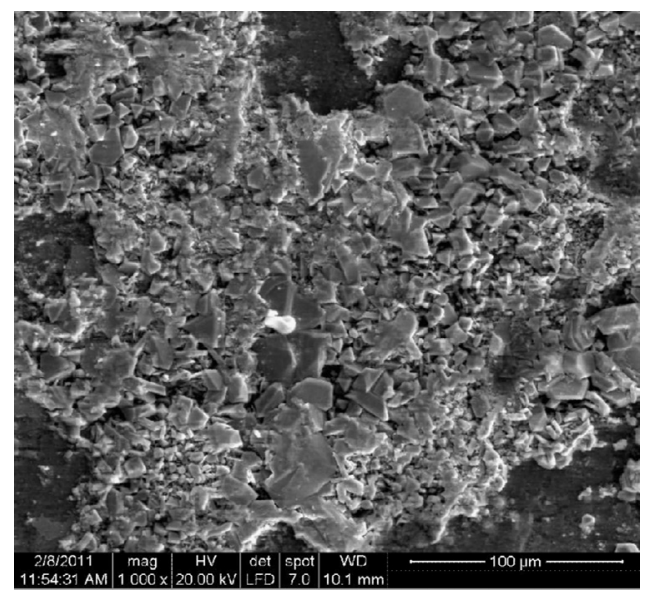

Fig. 9. SEM image of the HDGS sample after 42 days of exposure in SSC $(1000 \times)$.

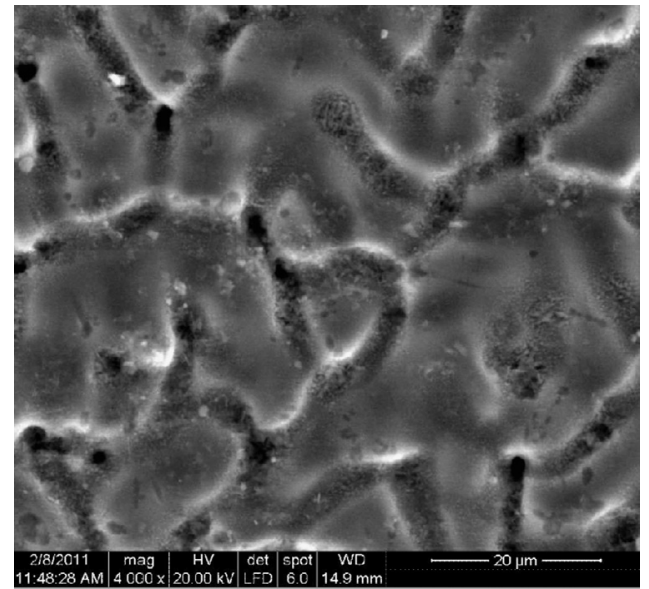

Fig. 10. SEM image of the HDZAS sample after 42 days of exposure in SSC $(4000 \times)$.

simonkolleite $\left(\mathrm{Zn}_{5}(\mathrm{OH})_{8} \mathrm{Cl}_{2} \cdot \mathrm{H}_{2} \mathrm{O}\right)$ [18-21]. Being very bulky, Fig. 9, this compound causes cleavage of the paint from the substrate in the areas where it is formed and increase pressure on adjacent areas, weakening the paint/substrate adhesion. Combined with a poor adhesion, that effect causes unsatisfactory protective ability in this medium. Conversely, when the electrolyte that contains anions $\mathrm{Cl}^{-}$is in contact with the HDZAS, hydrozincite $\left(\mathrm{Zn}_{5}\left(\mathrm{CO}_{3}\right)_{2}(\mathrm{OH})_{6}\right)$ is formed in the interdendritic zones and precipitates forming small acicular crystals, Fig. 10. Zinc aluminum carbonate $\left(\mathrm{Zn}_{6} \mathrm{Al}_{2}(\mathrm{OH})_{16} \mathrm{CO}_{3} \cdot 4 \mathrm{H}_{2} \mathrm{O}\right)$, the major corrosion product, is then formed onto all the surface. This compound has a crystalline and compact structure [22]. This fact, in conjunction with a better substrate/paint adhesion, makes the delamination progress much slower than in the HDGS. Pretreated with MTMO, the HDGS notably improves its adherence to the paint; this fact was revealed by the dry adhesion results and also by the difference found in the propagation rate of the paint film delamination when this substrate is pretreated with MTMO. It was thus concluded from the above results that the "MTMO/paint" and "MTMO/substrate" adhesion values are higher than the "substrate/paint" adhesion value. From this experimental evidence the following question arose "in which interface does adhesion failure occur? To answer this question the paint film was removed from a blister and EDXS analysis were conducted on the side of the delaminated paint film facing the substrate and the area of the substrate under the blister. Fig. 11 allows observing that after 42 days of exposure in SSC, the EDXS spectra of the HDGS and HDZAS layers do not exhibit the peak corresponding to $\mathrm{Si}$, the major component of MTMO, thus indicating that the formation of blisters causes the MTMO film also peels off from the substrate. Conversely, the same type of analysis conducted on the paint film revealed the presence of Si, Fig. 12. This fact demonstrates adhesion failures in the MTMO/substrate but not in the MTMO/paint interface.
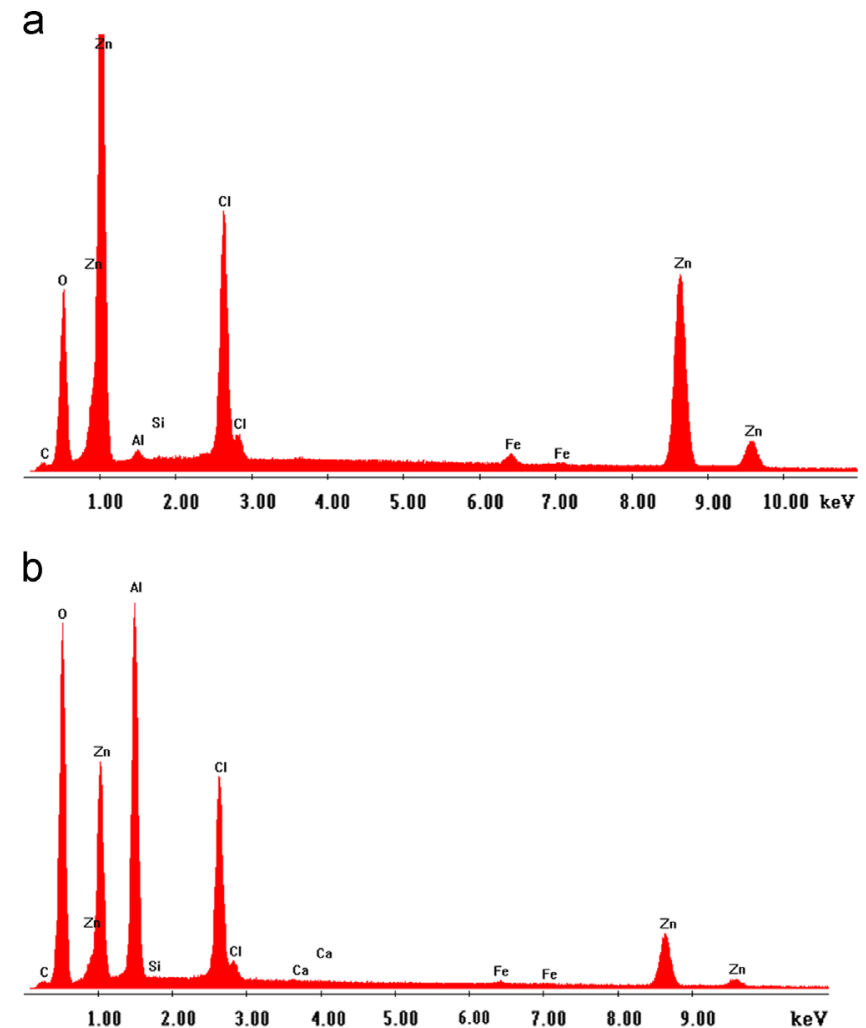

Fig. 11. EDXS spectra of the substrate under a blister after 42 days of exposure in SSC; (a) HDGS, (b) HDZAS.

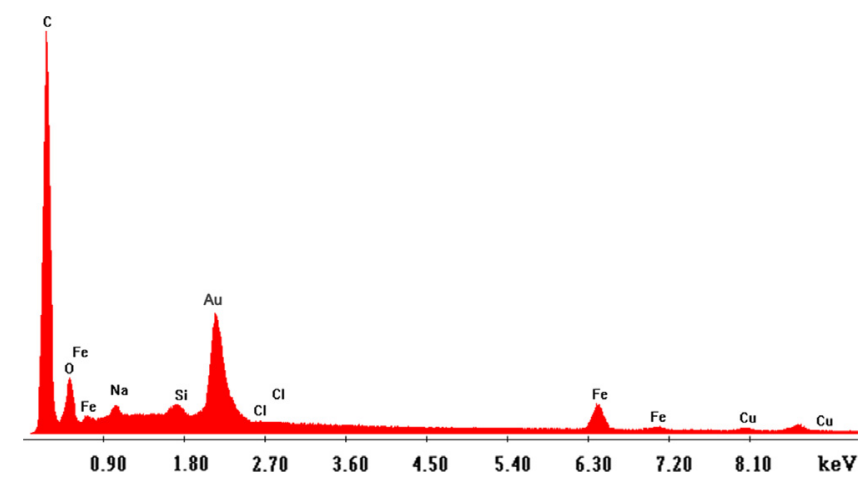

Fig. 12. EDXS spectra of a paint sample, substrate side, obtained from a blister after 42 days exposure in SSC. 
The corrosion products observed by SEM in the samples pretreated or not with MTMO had the same morphology. This was attributed to the fact that when the blistering occurred, the substrate became exposed to the corrosive medium since the MTMO film peeled off in conjunction with the paint. Thus, it can be inferred that improvement in the behavior of these systems against corrosion takes place because the adhesion forces are greater in the MTMO/substrate than in paint/substrate interface; however, once the adhesion failures as well as the blistering occur, the corrosion process under the blisters does not change independently of the fact that the substrate has been or has been not pretreated. Either pretreated or not with MTMO, the behavior against corrosion of HDZAS systems was similar and in accordance with the paint/substrate and MTMO/substrate adhesion forces, which showed similar values (Table 2 ).

\section{Conclusions}

The above results clearly showed that MTMO is a good promoter of the adhesion between water-based polyurethane paints and zinc coatings.

In the HDZAS samples no significant effect of the MTMO was found on the adhesion, since this property is adequate without pretreatment. In the $\mathrm{HC}$ test, the absence of an aggressive anion made that all the duplex systems had similar behavior. Conversely, in presence of $\mathrm{Cl}^{-}$the HDZAS provided a better protective performance due to the formation of compact corrosion products diminished the paint delamination rate.

In the HDGS samples, the bulky corrosion products in conjunction with the poor paint adhesion produced a fast paint delamination. The presence of MTMO in the metal/paint interface improved the behavior of the HDGS + MTMO system against corrosion in a medium with $\mathrm{Cl}^{-}$, since it promotes stronger adhesion bonds and, hence, causes slower delamination rate when the paint defects appear.

The adhesion failures in both systems occurred in the zinc layer/MTMO interface. Even though the pretreatment increases the useful life of these systems due to an improvement of the adhesion properties, when the latter fail the corrosion process is not affected since the film promoting adhesion peels off in conjunction with the paint.

\section{Acknowledgements}

The authors thank to the Comision de Investigaciones Científicas de la Provincia de Buenos Aires (CICPBA), the Consejo Nacional de Investigaciones Científicas y Técnicas (CONICET), and the La Plata University (UNLP) by the financial support to carry out the present research paper. The authors also thank to A. Campbell from Camsi-X for the supply of the silane.

\section{References}

[1] Bird CE, Strauss FJ. Effect of wet storage staining on the subsequent corrosion rate of galvanized iron sheets. Mater Performance 1976;15(11):27-9.

[2] Seré PR, Culcasi JD, Elsner CI, Di Sarli AR. Study of the corrosion process at the galvanized steel/organic coating interface. Proceedings of SCANNING 98, Baltimore-Maryland, USA. J Scanning Microsc 1998;20(3):274-5.

[3] Suzuki I. The behavior of corrosion products on zinc in sodium chloride solution. Corros Sci 1985;25(11):1029-34.

[4] van Eijnsbergen JFH. Adhesion and adhesion testing. New York, NY: Elsevier Science B.V. "Duplex Systems-Hot Dip Galvanising Plus Painting,"; 1994; 75-116.

[5] Jourdan BP, Elsner CI, Di Sarli AR. Evaluación de la influencia del pretratamiento superficial sobre la capacidad anticorrosiva del sistema duplex, Anales de las. Jornadas SAM/CONAMET 2001, Posadas-Misiones, Argentina 2001;2: 723-30.

[6] Sacco EA, Culcasi JD, Elsner CI, Di Sarli AR. Evaluation of the protective performance of several duplex systems exposed to industrial atmosphere. Lat Am Appl Res 2002;32(4):307-11.

[7] Toxicological profile for chromium, agency for toxic substances, U.S. Public Health Service, report no. ASTSDR/TP-88/10.

[8] Dave BC, Hu XK, Devaraj Y, Dhali SK. Sol-gel-derived corrosion-protection coatings. J Sol-Gel Sci Technol 2004;32(1-3):143-7.

[9] Conde A, De Damborenea J, Duran A, Menning M. Protective properties of a sol-gel coating on zinc coated steel. J Sol-Gel Sci Technol 2006;37(1):79-85.

[10] Chico B, de la Fuente D, Pérez ML, Morcillo M. Corrosion resistance of steel treated with different silane/paint systems. J Coat Technol Res 2012:9:3-13.

[11] Wang L, Liu Cs, Yu H-y, An C-q. Structure and corrosion resistance of a composite g-amino propyl triethoxy silane and $\gamma$ g-glycidoxy propyl trimethoxy silane conversion coating on galvanized steel. J Iron Steel Res Int 2012;19:46-51.

[12] Bexell U, Grehk T Mikael. A corrosion study of hot-dip galvanized steel sheet pre-treated with $\gamma$-mercaptopropyltrimethoxysilane. Surf Coat Technol 2007:201:4734-42.

[13] Barceló G, Sarret M, Müller C. Corrosion resistance and mechanical properties of zinc electrocoatings. Electrochim Acta 1998;43:13-20.

[14] Kendig MW, Ryang H-S, Liao T-L, Jeanjaquet SL. Comparison of corrosion protection provided by a non-volatile organic compound epoxy and a marine epoxy primer. Corrosion 1999;55(3):222-8.

[15] Almeida E, Fedrizzi L, Diamantino TC. Oxidising alternative species to chromium VI in zinc-galvanised steel surface treatment. Part 2-An electrochemical study. Surf Coat Technol 1998;105(1-2):97-101.

[16] Magalhaes AAO, Margarit ICP, Mattos OR. Electrochemical characterization of chromate coatings on galvanized steel. Electrochim Acta 1999;44(24):4281-7.

[17] van Ooij WJ, Zhu D, Stacy M, Seth A, Mugada T, Gandhi J, et al. Corrosion protection properties of organofunctional silanes-an overview. Tsinghua Sci Technol 2005;10(6):639-64.

[18] Almeida E, Pereira D. The degradation of zinc coatings in salty atmospheres. Prog Org Coat 1989;17(2):175-89.

[19] Seré PR, Culcasi JD, Elsner CI, Di Sarli AR. Relationship between texture and corrosion resistance in hot-dip galvanized steel sheets. Surf Coat Technol 1999;122:143-9.

[20] Asgari H, Toroghinejad MR, Golozar MA. Effect of coating thickness on modifying the texture and corrosion performance of hot-dip galvanized coatings. Curr Appl Phys 2009:9:59-66.

[21] Asgari H, Toroghinejad MR, Golozar MA. Relationship between (00.2) and (20.1) texture components and corrosion resistance of hot-dip galvanized zinc coatings. J Mater Process Technol 2008;198:54-9.

[22] Seré PR, Zapponi M, Elsner CI, Di Sarli AR. Comparative corrosion behaviour of 55 aluminium-zinc alloy and zinc hot-dip coatings deposited on low carbon steel substrates. Corros Sci 1998;40(10):1711-23. 